\title{
The Effect of Human Platelet-Rich Plasma and L-Ascorbic Acid on Morphology, Proliferation, and Chondrogenesis Ability towards Human Adipose-Derived Stem Cells
}

\author{
Imam Rosadi ${ }^{1,2}$, Karina ${ }^{2,3}$, lis Rosliana ${ }^{2}$, Siti Sobariah², Irsyah Afini², Tias Widyastuti², \\ Anggraini Barlian $^{1}$ \\ ${ }^{1}$ Department of Biotechnology, School of Life Sciences and Technology, Institut Teknologi Bandung, Bandung, Indonesia \\ ${ }^{2}$ Hayandra Laboratory, Hayandra Clinic, Hayandra Peduli Foundation, Jakarta, Indonesia \\ ${ }^{3}$ Doctoral Program in Biomedical Science, Faculty of Medicine, Universitas Indonesia, Jakarta, Indonesia
}

Background: Microtia is a congenital malformation in the external ear due to cartilage defect. Adipose-derived stem cells (ADSC) is promising cells to develop cartilage tissue engineering for microtia. In this study, we focused on proliferation and chondrogenesis of ADSC in three different media, which consist of $10 \%$ fetal bovine serum (FBS), $10 \%$ FBS with L-ascorbic acid, and $10 \%$ human platelet rich plasma (PRP).

Materials and Methods: ADSC were induced to differentiate into adipocytes, chondrocyte and osteocytes. ADSC morphology, proliferation and population doubling time was compared in three different media and analysed. Observation and alcian blue staining were done every 7 days to assess chondrogenic potency of ADSC from each treatment.

Results: Isolated ADSC were able to differentiate into adipocytes, osteocytes and chondrocytes. ADSC in all group have fibroblast-like morphology, but cells in $10 \%$ FBS and $10 \%$ FBS with LAA group were flattened and larger. ADSC in $10 \%$ PRP group proliferates faster than 10\% FBS with and without LAA. PDT values of ADSC were 34 hours, 44 hours and 48 hours, respectively for $10 \%$ PRP, $10 \%$ FBS with LAA and 10\% FBS group. Alcian blue staining revealed that ADSC in $10 \%$ FBS with LAA and $10 \%$ PRP were able to proceed to chondrogenesis when cultured time were prolong up to 21 days, but not with ADSC in $10 \%$ FBS.

Conclusion: We conclude that adding 10\% FBS with LAA or 10\% PRP into medium culture can support proliferation and chondrogenesis of ADSC.

Keywords: human ADSC, PRP, L-ascorbic acid, proliferation, chondrogenesis

\section{Introduction}

Microtia is a congenital malformation of outer ear caused by genetic and environment factor that belonging to birth defect category ${ }^{1,2}$ The prevalence of microtia is about 0.83 to 17.4 per 10.000 which impacted on hearing loss. ${ }^{2,3}$ Implantation of autologous rib cartilage was common for ear reconstruction. ${ }^{4,5,6}$ Four rib cartilage were harvested,

Date of submission: October 26, 2018

Last Revised: November 28, 2018

Accepted for publication: November 28, 2018

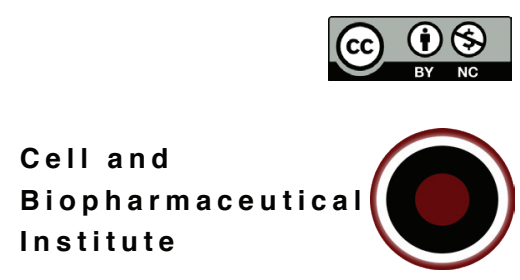

Corresponding Author:

Imam Rosadi

Department of Biotechnology

School of Life Sciences and Technology, Institut Teknologi Bandung

Jl. Ganeca No.10, Lb. Siliwangi, Bandung, Indonesia

E-mail: imamrosadi@s.itb.ac.id 
curved and transplanted as new ear whereas this technique was invasive and risky. ${ }^{6}$ Tissue engineering strategies utilize cells, nutrient, and scaffold to generate cartilage for replacing the use of rib. Ideally, cells for cartilage generation harvested from cartilage tissue. Due to the lack of cartilage in the body and the poor regenerative capability, stem cells have become an alternative source of chondrocytes, a cartilage component building. ${ }^{7,8}$

The most common adult stem cells that were developed are adipose-derived stem cells (ADSC) and bone marrow mesenchymal stem cells (BMSC) that has less ethical issue. ${ }^{8}$ ADSC and BMSC had similar morphology and proliferation and shared some similar surface marker. Both also can be differentiated towards various cells like adipocytes, chondrocytes, and osteocytes under appropriate conditions. ${ }^{9,10}$ Compared to the BMSC, harvesting the source of ADSC, which is fat is obviously less invasive. Moreover, ADSC can be isolated in larger number than BMSC. . $^{10,11,12}$

According to Pawitan, et al., platelet-rich plasma (PRP) can induce differentiation of ADSC to chondrocytes lineage. ${ }^{13} \mathrm{PRP}$ can be used to substitute FBS for promoting cells proliferation and migration because it contains many growth factors. ${ }^{14}$ At least, these transforming growth factor- $\beta 1$ (TGF- $\beta 1$ ), platelet-derived growth factor (PDGF), epidermal growth factor (EGF), insulin-like growth factor-1 (IGF-1), vascular endothelial growth factor (VEGF) were contained in PRP. Moreover, Sari, et al., has reported that level of TGF- $\beta 1$ is the highest among all growth factors in PRP. ${ }^{15}$ TGF- $\beta 1$ is the ligand for inducing chondrogenesis of ADSC. ${ }^{16}$ However, the efficacy of $10 \%$ PRP supplementation has not been compared with other reported chondrogenesisinducing agent, such as L-ascorbic acid (LAA). L-ascorbic acid supplementation with $10 \%$ fetal bovine serum (FBS) reported induced chondrogenesis ADSC. ${ }^{17}$ This study was done to analyze the effect of 10\% PRP supplementation compare to L-ascorbic acid supplementation with $10 \%$ FBS and $10 \% \mathrm{FBS}$ only as control on proliferation and promotion of chondrogenesis of ADSC.

\section{Materials and methods}

\section{Isolation, Culture and Expansion of ADSCs}

This is an experimental study, conducted in Hayandra Lab Laboratory, Hayandra Peduli Foundation, Jakarta, required lipoaspirates from three healthy donors. All procedures and manipulations were approved by The Health Research
Committee Faculty of Medicine Universitas Padjajaran Bandung (No. 666/UN6.C.10/PN/2017). Stromal vascular fraction (SVF) was isolated from lipoaspirates of three healthy patients using enzymatic method as reported in a previous publication. ${ }^{18}$ Isolated cells were seeded in basic growth medium which contained low glucose (1 g/L) Dulbecco's Modified Eagle Medium (DMEM) with L-glutamine (4 mM) (Gibco), 10\% FBS (Gibco) and 1X antibiotic-antimycotic (Gibco) and incubated at $37^{\circ} \mathrm{C}, 5 \%$ $\mathrm{CO}_{2}$. Media was changed every 2-3 days. After cells reached $80-90 \%$ confluency, the cells were sub-cultured. Cells were expanded up to passages 2 for next assay.

\section{Multipotency Assays}

ADSC passages 2 were cultured in $24-w e l l$ plate $\left(1 \times 10^{4}\right.$ cells/ well) in basic growth medium. Medium was changed every 2-3 days. After cells reached $80 \%$ confluency, medium was replaced with chondrogenic induction medium (StemPro Chondrogenesis Differentiation Kit), osteogenic induction medium (StemPro Osteogenesis Differentiation Kit), and adipogenic induction medium (StemPro Adipogenic Differentiation Kit) for 7 days. The cells were fixed in formalin $10 \%$ and then stained with oil red $\mathrm{O}$, alcian blue, alizarin red for adipocytes, chondrocytes and osteocytes, respectively. Observation of cell differentiation was done using inverted microscope (OPTICA microscope).

\section{Morphology and Proliferation Assay}

In this study, we compared the effect of three different growth medium, including 10\% outdated red-cross PRP, 50 $\mu \mathrm{g} / \mathrm{mL}$ L-ascorbic acid (LAA) with $10 \%$ FBS and 10\% FBS only as control on ADSC morphology and proliferation. Morphology observation of ADSC in three experimental medium was performed using OPTICA microscope (100X). The 50 cells spread size was calculated using ImageJ program. Trypan blue staining and 3-(4,5-Dimethylthiazol2-yl)-2,5-Diphenyltetrazolium Bromide (MTT) assay were done to evaluate cells proliferation.

\section{Trypan Blue Staining}

Cells were seeded and cultured in 24-well plate $\left(1 \times 10^{4}\right.$ cells/ well) up to 21 days. Cells were harvested on day 1, 2, 3, 4, $5,6,7,14,21$. Viable and non-viable cells were counted using Trypan blue staining method and used to calculate cell population doubling time (PDT) value. PDT value was calculated using the following equation : 


$$
\mathrm{PDT}=\frac{\log 2 x \Delta \mathrm{t}}{\log (\mathrm{NH})-\log (\mathrm{NI})}
$$

$\Delta \mathrm{t} \quad=$ time from seeding to harvesting

$\mathrm{NH}=$ harvested cells number

$\mathrm{NI}=$ seeded cells number

\section{MTT Assay}

Cells were cultured in 96 -well plates $\left(5 \times 10^{3}\right.$ cells/well $)$ in three experimental medium up to 21 days. Viable cells were counted on day $1,3,5,7,14$, and 21 for proliferation rate analysis. For this, MTT solution $(25 \mathrm{mg} / \mathrm{mL}$ ) (SigmaAldrich) was added to each well, followed by incubation for 4 hours at room temperature in the dark until violet crystal was formed. Violet crystal was dissolved in Dimethyl Sulfoxide solution (100 $\mu \mathrm{L}$ per well) (Sigma-Aldrich) for 10 minutes at room temperature. Optical density was directly measured at a wavelength of $595 \mathrm{~nm}$ using microplate reader within 10 minutes (Biorad iMark). Assay was done triplicate for each treatment.

\section{Chondrogenesis Assay}

Cells were cultured in 24-well plate $\left(10^{4}\right.$ cells/well $)$ and stained with alcian blue staining as described previously on day 7,14 , and 21 and observed using inverted microscope (OPTICA microscope).

\section{Statistics}

Normality test was done before any comparison test. Normally distributed data with homogenous variance of three experimental groups were compared using analysis of variance (ANOVA) test. Significant difference were determined if $p$-value less than 0.05 . Post hoc-analysis was done by the least significant difference (LSD) test.

\section{Results}

\section{Cells Differentiation into Adipocyte, Chondrocyte and Osteocyte Lineage}

We began to notice there were some cells within cultured isolated SVF adhered to the flask after 3 days and it has similar morphology with fibroblast. The cells were expanded up to passage 2 before use for any assay, later on, these passages 2 plastic adherent cells were induced to differentiate into adipocyte using adipogenic medium. After 7 days induction, the morphology of cells was changed to be more rounded with many red lipid droplets in the cytoplasm after Oil Red O staining, confirming cells differentiation into adipocyte (Figure 1A). We also began to observe a lot of extracellular cartilage matrix (Figure 1B) and calcification (Figure 1C) when the cells were cultured in chondrogenic and osteogenic media, respectively, over 7 days after the cells confluency about $80 \%$. Later on, these cells were called as ADSC.

\section{Effect of Culture Media to the Change of Morphology and Cells Proliferation}

On day 3 , cultured ADSC in $10 \%$ PRP, LAA with $10 \%$ FBS and $10 \%$ FBS only were all fibroblast-like spindle-shaped cells. After 6 days, the size of ADSC in 10\% FBS began to be larger than ADSC in $10 \%$ PRP $\left(0.0385 \pm 0.015 \mathrm{~mm}^{2}\right.$, $0.00372 \pm 0.002 \mathrm{~mm}^{2}, p=0.000$, ANOVA one-way) and LAA with $10 \%$ FBS group $\left(0.00476 \pm \mathrm{SD} \mathrm{mm}^{2}, p=0.000\right.$, ANOVA one-way) as shown in Figure 2. We also observed that ADSC in LAA with $10 \%$ FBS group were larger than ADSC in $10 \%$ PRP group ( $p=0.001$, ANOVA one-way). After 6 days, ADSC in 10\% PRP group were small, considered healthy with a lot of immature cells with bright light around the cells, microscopically different compared to all FBS group.
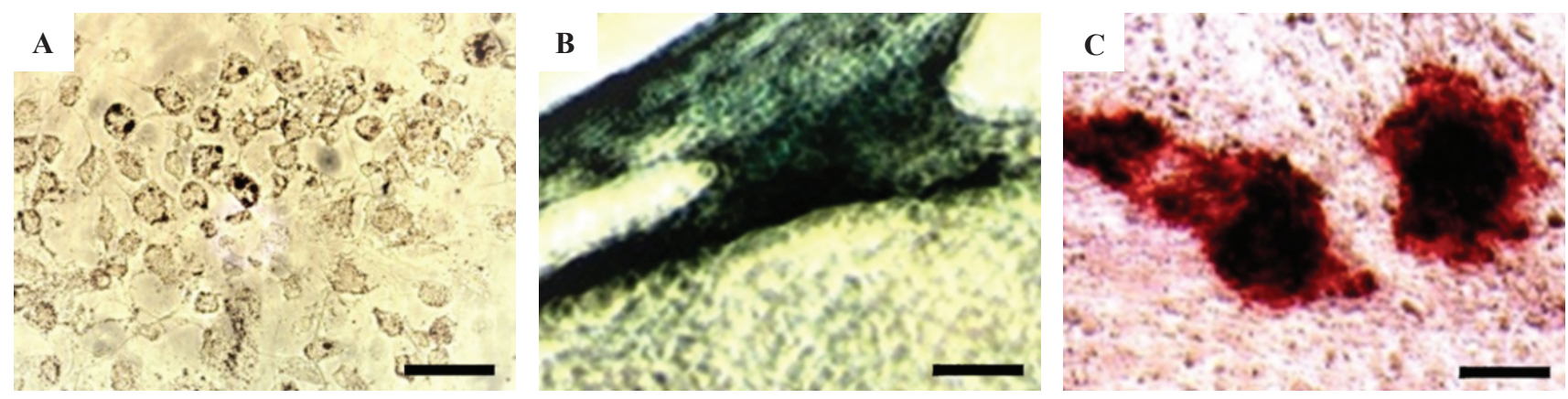

Figure 1. Differentiation of adipose derived stem cells with induction media on day 7. A: adipocyte; B: chondrocyte; C: osteocyte. Black bar: $100 \mu \mathrm{m}$. 

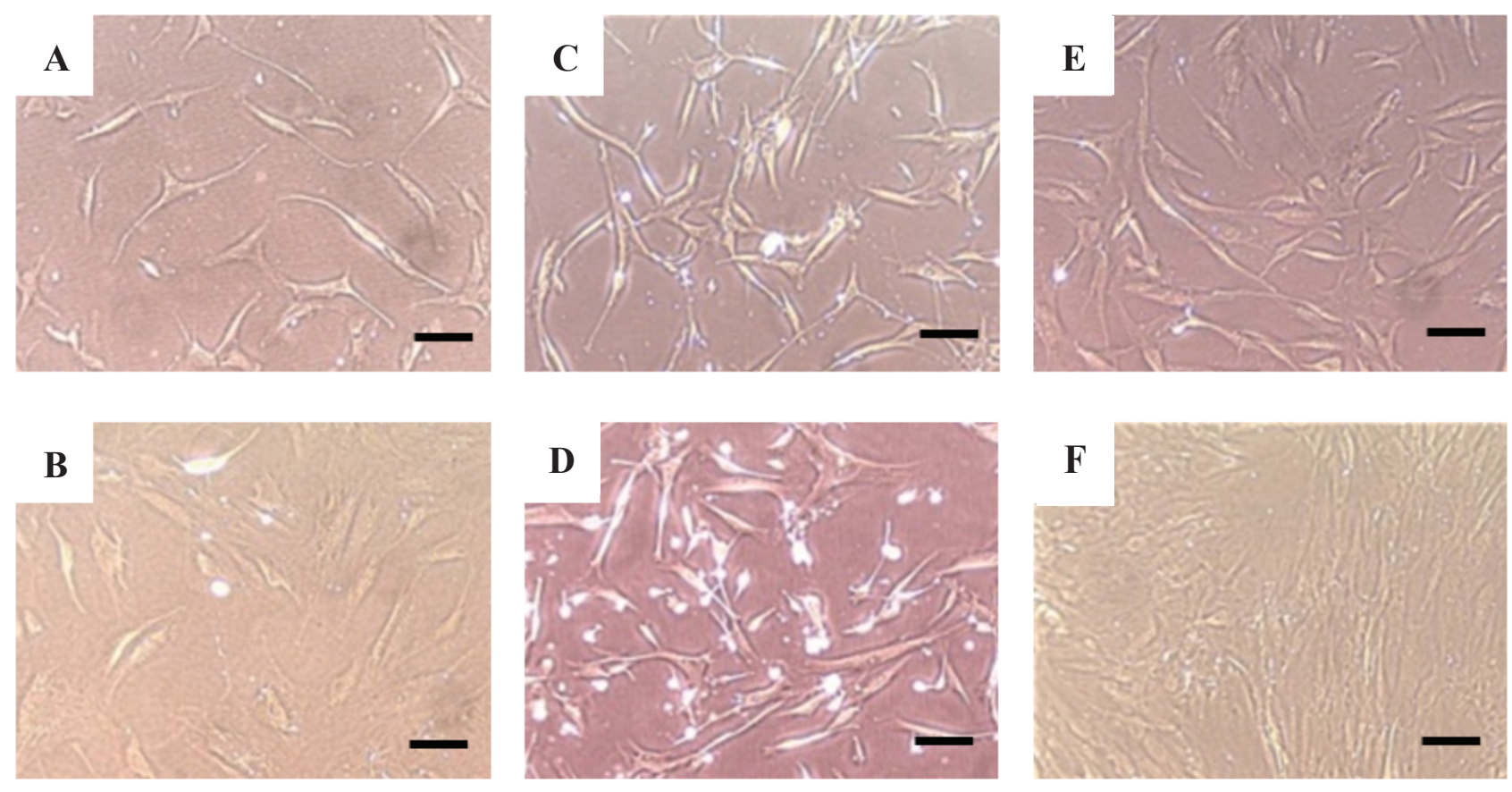

G

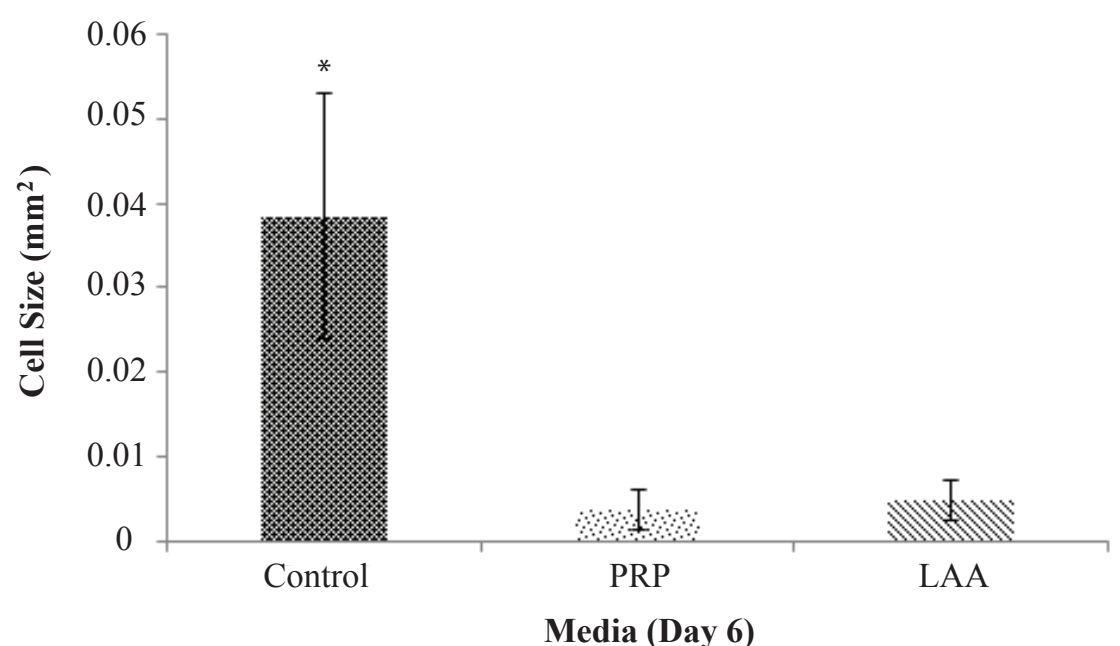

Figure 2. Change of Morphology and Cells Proliferation. ADSC in $10 \%$ FBS (A-B), 10\% PRP (C-D), LAA with $10 \%$ FBS (E-F). Cells morphology were observed on day $3(\mathrm{~A}, \mathrm{C}, \mathrm{E})$ and day $6(\mathrm{~B}, \mathrm{D}, \mathrm{F})$ in 24-well plate. The cells spread size in various media was performed by Image J (G). Black bar: $100 \mu \mathrm{m}$. *The results were significantly different with $p$-value $<0.01$.

Proliferation of ADSC in each experimental group evaluated up to 21 day. The results were presented in Figure 3. It can be seen that $10 \%$ PRP supplementation can increase proliferation of ADSC.

From day 5 to day 21, cells number in 10\% PRP group was highest among all FBS group. At day 21, cells number in $10 \%$ PRP group (220.740 \pm 45.668 cell number for PRP) was significantly different compared to control $(62.600 \pm 16.257$ cell number for control, $p=0.002$ ) and ADSC in LAA with $10 \%$ FBS group $(112.592 \pm 42.533$ cell number for LAA, $p=$
0.012). Proliferation of ADSC in $10 \%$ FBS group was the slowest among all groups. ADSC in $10 \% \mathrm{FBS}$ group was the largest in size and reached its maximum confluency earlier than other group on day 14. After 14 days onward, cells in this control group did not have enough space to expand and leads to cell death causes a reduction in cells number on day 21. We calculated PDT value of ADSC from each group and found that ADSC in $10 \%$ PRP, LAA with $10 \%$ FBS and $10 \%$ FBS group needed 34,44 and 48 hours to double the cells number. 


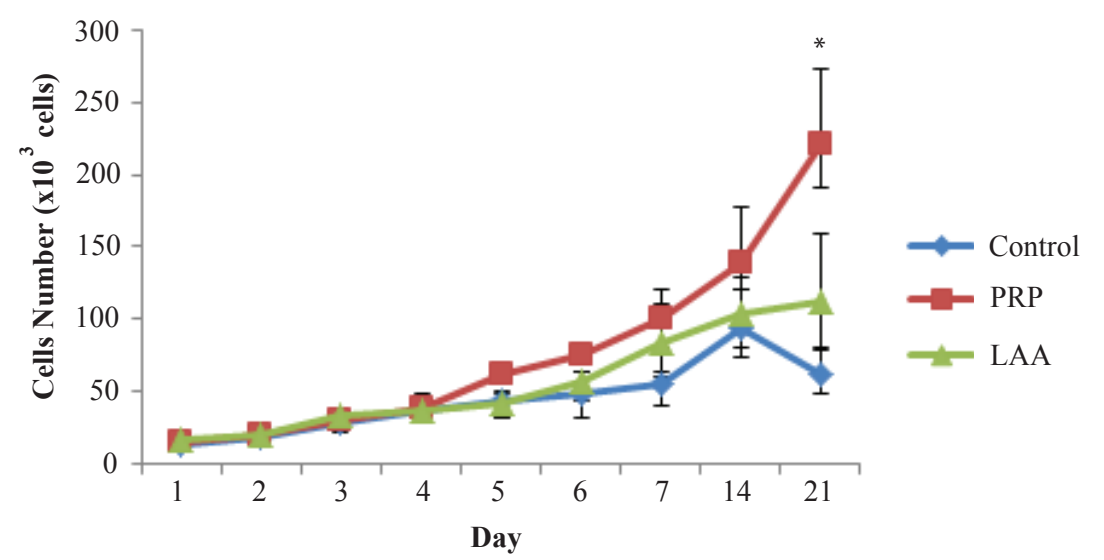

Figure 3. Total cells number in three experimental groups. *Average cells number was significantly different compared to control $p$-value 0.002 and LAA groups with $p$-value 0.012 .
MTT assay results represented viable cells number of ADSC in each group (Figure 4). Absorbance at $595 \mathrm{~nm}$ was proportionate with number of viable cells. ADSC in $10 \%$ PRP group has significantly higher absorbance began on day 5 to 21, compared to ADSC in $10 \%$ FBS control and LAA with $10 \%$ FBS groups. This data was consistent with Trypan blue staining result, confirming that $10 \%$ PRP supplementation increasing proliferation and cells viability.

\section{Effect of Three Experimental Media to Chondrogenesis Potency of ADSC}

The potency of PRP to promote chondrogenesis of ADSC was observed and compared to potency of LAA with $10 \%$ FBS and control group, based on the formation and accumulation of glycosaminoglycan matrix (Figure 5). In chondrogenesis process, ADSC will be retracted to each other forming micromass at the periphery and the centre of the well. Cells retraction was not found on day 14 in $10 \%$ PRP group, but blue-stained glycosaminoglycan matrix was noticed. On day 21, cells retraction was found at the periphery of well forming micromass in 10\% PRP group. Cells in micromass were almost visible in this $10 \%$ PRP group. In LAA with 10\% FBS group, cells retraction began to form at the periphery of well on day 14 , earlier than $10 \%$ PRP group. On day 21 , more cells were retracted to each other forming larger micromass than micromass on day 14 , but the cells inside the micromass was still visible. However, intensity of blue-stained glycosaminoglycan matrix in LAA with $10 \%$ FBS group was lower compared to $10 \%$ PRP group. We did not observe any cells retraction or blue-stained glycosaminoglycan matrix in 10\% FBS control group. These data indicated that both of $10 \%$ PRP and LAA with $10 \%$ FBS were able to promote chondrogenesis of ADSC, but not with $10 \%$ FBS only.

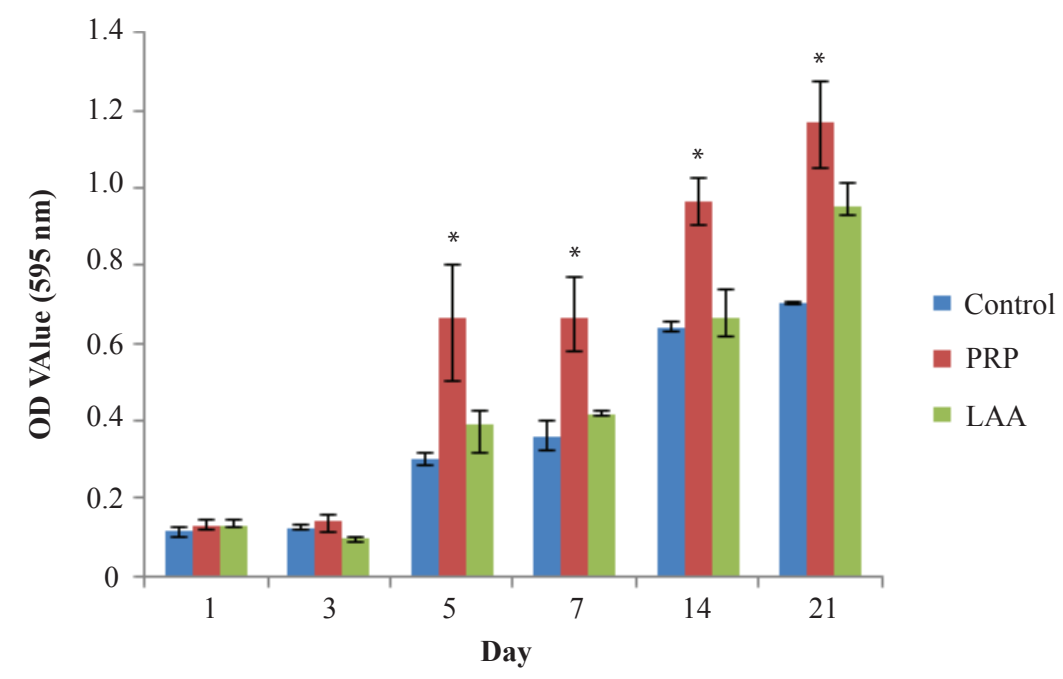

Figure 4. Cells absorbance of ADSC in three experimental groups representing viable cells proliferation. *Average absorbance on day 21 was significantly different compared to control and LAA groups with $p$-value $<0.05$. 

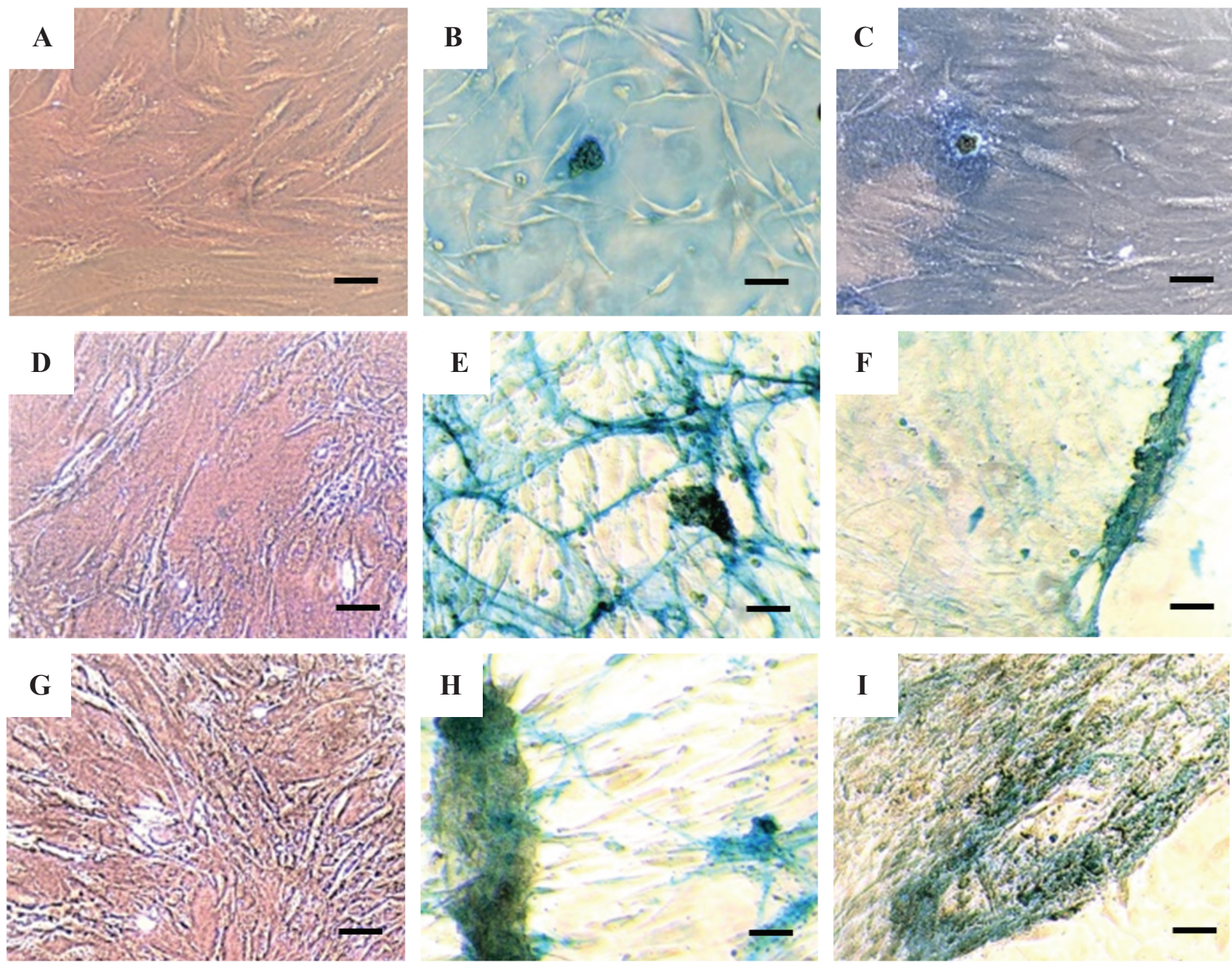

Figure 5. Chondrogenesis of ADSC on day 7 (A-C), 14 (D-E) and 21 (F-G) using alcian blue staining in three experimental medium. A,D,G: control; B,E,H: PRP; C,F,I: LAA. Black bar: $100 \mu \mathrm{m}$.

\section{Discussion}

Both of PRP and LAA have been shown to affect the chondrogenesis of ADSC in many studies. ${ }^{13,17}$ However, as far as we know there was no research report that compared the effect of PRP and LAA in one ADSC chondrogenesis study. In this study, we investigated the effect of these two chondrogenic supplements.

Proliferation is key factor in chondrogenesis process. Pawitan, et al., reported that ADSC should proliferate until reaching its maximum confluency and then cells retraction occurs forming a micromass. ${ }^{13}$ Both of $10 \%$ PRP and LAA with $10 \%$ FBS were able to increase the proliferation of ADSC, with pro-proliferation effect was higher in 10\% PRP group compared to LAA with $10 \%$ FBS group. However, we observed that ADSC in 10\% PRP group was healthier, smaller with normal fibroblast-like morphology that was microscopically different with ADSC in LAA with $10 \%$ FBS group that showed senescence sign. Cells senescence normally occurred due to repeated cells division that widely known as Hayflick phenomenon. ${ }^{19}$ This hayflick phenomenon was even prominent in 10\% FBS control group. Over 14 days, larger cells already filled at most of the surface area of the well culture. On day 21, cells in control group were begun to death resulting a reducing of cells number compared to day 14 .

At the other hand, after 14 days, ADSC in $10 \%$ PRP and LAA with $10 \%$ FBS group still proliferated. Cells become retracted to each other in these two experimental groups. We noticed that prominent cells retraction was occurred earlier in LAA with $10 \%$ FBS group than in $10 \%$ PRP group on day 14. However, on day 21, a micromass 
formed in 10\% PRP group was thicker and bigger than in LAA with $10 \%$ FBS group until we could be barely seen the cells within the micromass in this $10 \%$ PRP group. This data indicates that chondrogenic rates of ADSC due to $10 \%$ PRP and LAA with $10 \%$ FBS supplementation were different.

In this study, we used $10 \%$ outdated PRP from Indonesian red-cross society, similar study was done by Pawitan, et al..$^{13}$ They reported that ADSC should be prolonged culture in $10 \%$ PRP medium until chondrogenesis occurred. ${ }^{13}$ Both of this and the previous study used PRP activation by freezing-thawing method. By this platelet activation method, growth factors were gradually released from the broken activated platelet, while the rest of platelet is still intact. We hypothesized that in culture medium, the growth factor released from broken platelet due to freezing thawing will be utilized first by ADSC to promote cells proliferation. Later on, rest of intact platelet after freezingthawing will be broken and released the rest part of growth factors and later on ADSC will be used these growth factors to support ADSC differentiation into chondrocyte lineage. Therefore, it takes longer for ADSC to differentiate into chondrogenesis, compared to LAA with $10 \%$ FBS or other chondrogenesis supplementation such VEGF and human $\mathrm{AB}$ serum which has been reported by Pawitan, et al..$^{20} \mathrm{It}$ should be taken into consideration that growth factors level in serum is higher than in plasma, because all the platelet have been activated during serum preparation time in the absence of anti-coagulation agent in blood collection tube. This might be responsible for faster chondrogenesis in serum stimuli.

LAA has other pathway to induce chondrogenesis. LAA will enter the cell via sodium-dependent vitamin C transporter (SVCT), such as SVCT1 and SVCT2. Human chondrocyte only express the SVCT2. In aqueous environment with the presence of oxygen, LAA is unstable and will be oxidized to dehydroascorbate (DHA). DHA will enter the cells via GLUT transport mechanism. ${ }^{21}$ In cytoplasm, LAA induces ADSC into chondrocyte lineage by promoting signalling cascade that can activate RUNX2. ${ }^{17}$

PRP contains TGF- $\beta 1$ level that was higher than any growth factors in PRP. ${ }^{15}$ TGF- $\beta 1$ is ligand that interacts with the TGF- $\beta 1$ receptor and induces chondrogenesis. PDGF is the second higher level growth factor within PRP. PDGF maintains the hyaline-like chondrogenic phenotype in chondrocytes as well as the synthesis of proteoglycan. ${ }^{22}$
The next main growth factor in PRP is VEGF that has been previously reported as a chondrogenic factor. ${ }^{20}$ These all growth factor might work synergistically along with other cytokines in PRP to promote cells proliferation and gradually increased chondrogenesis producing higher effect than LAA with $10 \%$ FBS supplementation.

\section{Conclusion}

In conclusion, these results indicate that PRP and FBS with LAA can induce chondrogenesis of ADSC. Proliferation of ADSC supplemented by $10 \%$ PRP was significantly faster than control and $10 \%$ FBS with LAA. Furthermore, we suggest to use $10 \%$ PRP instead of $10 \%$ FBS with LAA for increasing cells proliferation and chondrogenesis of ADSC.

\section{Acknowledgment}

The authors greatly appreciated the grant and scholarship from the Indonesia Endowment Fund for Education (LPDP). We highly appreciated to Hayandra Peduli Foundation, Hayandra Laboratory which was facility the research, and greatly indebted for the cooperation of the lipoaspirate donors of their lipoaspirate donation.

\section{References}

1. Hildner F, Albrecht C, Gabriel C, Redl H, van Griensven M. State of the art and future perspectives of articular cartilage regeneration: a focus on adipose-derived stem cells and platelet-derived products. J Tissue Eng Regen Med. 2011; 5(4): e36-51.

2. Pawitan JA, Suryani D, Wulandari D, Damayanti L, Liem IK, Purwoko RY. Prolonged culture in FBS and FBS-substitute containing media: spontaneous chondrogenic differentiation of adipose tissue derived mesenchymal stem cells. Int J Pharm Tech Res. 2014; 6(1): 224-35.

3. Rauch C, Feifel E, Amann EM, Spötl HP, Schennach H, Pfaller W, et al. Alternatives to the use of fetal bovine serum: human platelet lysates as a serum substitute in cell culture media. ALTEX-Altern Animal Ex. 2011; 28(4): 305-16.

4. Sari P, Luviah E, Nugraha Y, Pawitan JA, Lilianty J, Purwoko RY. Various growth factor yields in various platelet rich plasma processing methods. Biotechnol. 2014; 9(11): 475-8.

5. Huang SJ, Fu RH, Shyu WC, Liu SP, Jong GP, Chiu YW, et al. Adipose-derived stem cells: isolation, characterization, and differentiation potential. Cell Transplant. 2013; 22(4): 701-9.

6. Nazempour A, Quisenberry CR, Abu-Lail NI, Van Wie BJ. Enhancing adipose stem cell chondrogenesis: a study on the roles of dexamethasone, transforming growth factor $\beta 3$ and ascorbate supplements and their combination. J Stem Cell Therapy Transplant. 2017; 1: 28-51.

7. Remelia M, Rosadi I, Sobariah S, Rosliana I, Karina. Method for Isolation of Regenerative Stromal Vascular Fraction from 
Human Subcutaneous Adipose Tissue. 2016. Poster presented to the 1st Annual International Conference and Exhibition on Indonesian Medical Education and Research Institute at Jakarta, Indonesia.

8. Wagner W, Horn P, Castoldi M, Diehlmann A, Bork S, Saffrich R, et al. Replicative senescence of mesenchymal stem cells: a continuous and organized process. PloS One. 2008; 3(5): 2213.

9. Pawitan JA, Suryani D, Lilianty J, Purwoko RY, Liem IK. T he use of VEGF supplemented media for chondrogenic differentiation of adipose derived mesenchymal stem cells. Biotechnol. 2013; 7(5): 169-73.

10. McNulty AL, Vail TP, Kraus VB. Chondrocyte transport and concentration of ascorbic acid is mediated by SVCT2. Biochim Biophys Acta Biomembr. 2005; 1712(2): 212-21.

11. Kon E, Buda R, Filardo G, Di Martino A, Timoncini A, Cenacchi A, et al. Platelet-rich plasma: intra-articular knee injections produced favorable results on degenerative cartilage lesions. Knee Surg Sports Traumatol Arthrosc. 2010; 18(4): 472-9. 